\title{
Amino acid levels in the brain of rats with peripheral nerve constriction or section
}

\author{
Mauro Bianchi MD, Paolo Ferrario PhD, Antonio Clavenna MD, Gabriele Biella MD, \\ Maria Luisa Sotgiu PhD
}

M Bianchi, P Ferrario, A Clavenna, G Biella, ML Sotgiu. Amino acid levels in the brain of rats with peripheral nerve constriction or section.

Pain Res Manage 1997;2(1):15-18.

BACKGROUND: Both excitatory and inhibitory amino acids modulate central neuronal activity following peripheral nerve tissue injury.

OBJECTIVE: To establish whether mononeuropathy induced by chronic constriction injury or by sectioning of the sciatic nerve affects neurotransmitter amino acid levels in the rat brain areas. METHODS: Glutamine, glutamic acid, gamma-aminobutyric acid (GABA) and aspartic acid in the hindbrain, midbrain and hypothalamus of rats were measured by high performance liquid chromatography 14 days after surgery.

RESULTS: After monolateral nerve ligation an increase in glutamine and a decrease in GABA levels in all brain areas were observed, with no side preference. The section of the sciatic nerve did not cause any modification in amino acid levels.

CONCLUSIONS: The results allow one to differentiate more clearly classic models of mononeuropathy from a biochemical point of view. Moreover, results indicate that continuous neuronal stimulation induced by nerve constriction is able to modify some amino acid pathways at a supraspinal level.

Key Words: Aspartic acid, Central nervous system, Gammaaminobutyric acid, Glutamic acid, Glutamine, Peripheral nerve injury, Rat

\section{Niveaux des acides aminés dans le cerveau de rats ayant subi une compression ou une section d'un nerf périphérique}

HISTORIQUE : Les acides aminés qu'ils soient inhibiteurs ou excitateurs modulent l'activité neuronale centrale à la suite d'une atteinte des tissus d'un nerf périphérique.

OBJECTIF : Fournir la preuve que la mononeuropathie induite par une lésion de compression chronique ou par la section du nerf sciatique a un effet sur les niveaux des acides aminés dans des parties du cerveau du rat.

MÉTHODES : On a mesuré les niveaux de glutamine, d'acide glutamique, d'acide gamma-aminobutyrique (GABA) et aspartique dans le rhombencéphale, le mésencéphale et l'hypothalamus de rats par chromatographie en phase liquide haute performance 14 jours après la chirurgie.

RÉSULTATS : Après une ligature monolatérale du nerf, on a observé une augmentation du niveau de glutamine et une diminution du niveau de GABA dans toutes les parties du cerveau, quel que soit le côté. La section du nerf sciatique n'a causé aucun changement dans les niveaux d'acides aminés.

CONCLUSIONS : Ces résultats nous permettent de différencier plus clairement les modèles classiques de mononeuropathies d'un point de vue biochimique. De plus, ils indiquent qu'une stimulation neuronale continue induite par la compression d'un nerf peut modifier certaines voies des acides aminés au niveau supraspinal.
Tnury of a peripheral nerve in humans is frequently associated 1 with abnormal pain sensations. In the past few decades several experimental studies have enabled the development of new therapies against neuropathic pain. However, neuropathic pain still con- stitutes a significant clinical problem. There are currently more than 30 animal models for neuropathic pain, characterized by specific combinations of anomalous behaviour that suggest the presence of spontaneous pain and abnormal responses to noxious and non-

Department of Pharmacology, University of Milano; and Institute of Neuroscience and Bioimaging, CNR, Milano, Italy

Correspondence and reprints: Dr M Bianchi, Department of Pharmacology, Via Vanvitelli, 32, 20129 Milano, Italy. Telephone 011-39-271-9750,

fax 011-39-273-0470, e-mail panerai@imiucca.csi.unimi.it

Received for publication June 5, 1996. Accepted December 12, 1996 


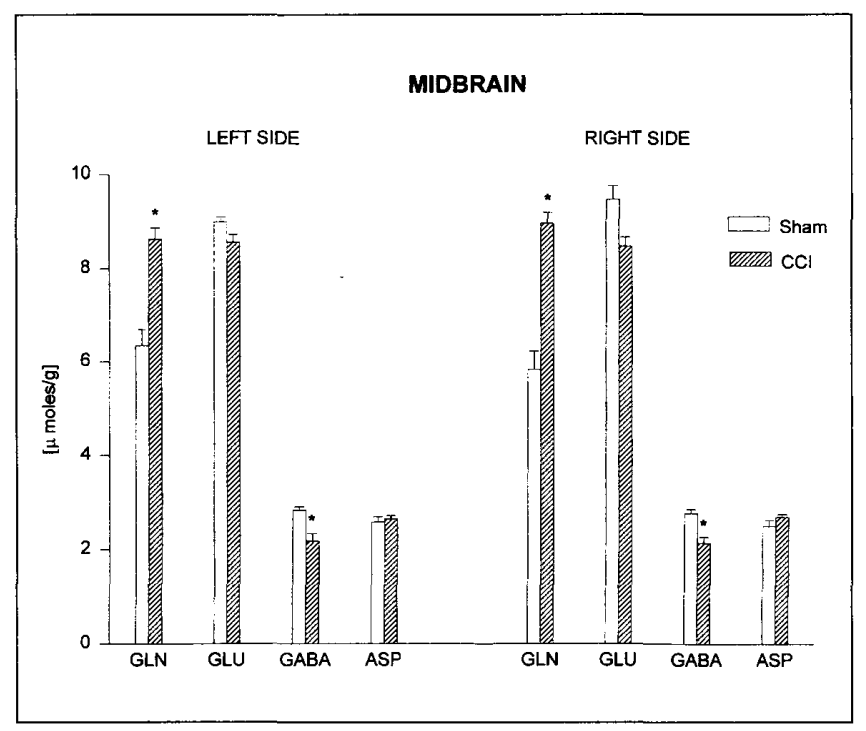

Figure 1) Amino acid levels measured in the rat midbrain 14 days after loose ligature of the right sciatic nerve. Values are presented as mean \pm SEM of eight rats. *Significantly different from sham-operated animals. ASP Aspartic acid; CCI Chronic constriction injury; GABA Gamma-aminobutyric acid; GLN Glutamine; GLU Glutamic acid

noxious stimuli (1). However, it is often difficult to define whether specific behavioural changes are truly associated with chronic pain. Thus, the study of biochemical modifications induced by different nerve manipulations may constitute an additional index for differentiating neuropathic syndromes. A classic experimental model of neuropathy is represented by the total denervation induced by sectioning of the sciatic nerve (2). Following complete deafferentation there is an increase in the spontaneous activity of dorsal horn cells and a functional reorganization at several central nervous system levels (3). More recently, an animal model that appears to reproduce behavioural and electrophysiological modifications similar to those observed in humans has been described $(4,5)$. In this model, the loose ligature of the sciatic nerve (chronic constriction injury [CCI]) is associated with several changes in the physiology of central somatosensory pathways $(6,7)$.

The possible biochemical modifications induced at a central level by peripheral neuropathy or noxious stimulation have been investigated mainly in the spinal cord $(8,9)$. Little information is available on the role and involvement of brainstem supraspinal structures in the experimental models of neurophatic pain. We $(10,11)$ have demonstrated that sectioning of the sciatic nerve and CCI produce a completely different neuropeptide response at a hypothalamic level. Both excitatory and inhibitory amino acids have been suggested as mediators of the transmission and control of noxious signals in the central nervous system $(12,13)$. We therefore measured the levels of aspartic acid, glutamic acid, glutamine and gamma-aminobutyric acid (GABA) in brain areas involved in the modulation of nociceptive transmission $(14,15)$ after chronic loose ligature of the sciatic nerve or sciatic nerve section in rats.

\section{ANIMALS AND METHODS}

Thirty-two male Sprague-Dawley rats (Charles River, Calco, Italy) weighing between 200 and $250 \mathrm{~g}$ were used. Rats were housed at $22^{\circ} \mathrm{C}$ with a $14 \mathrm{~h}$ light: $10 \mathrm{~h}$ dark cycle and had water and food ad libitum. The animals were anesthetized with intraperitoneal pentobarbital $40 \mathrm{mg} / \mathrm{kg}$. For induction of constriction injury of sciatic nerve, the loose ligation of right sciatic nerve was performed in a group of eight rats according to the technique of Bennett and Xie (4); another group of eight rats received a sham procedure in which the sciatic nerve was exposed without ligature. For induction of deafferentation, eight rats had $1 \mathrm{~cm}$ of the right sciatic nerve sectioned (starting from its point of entrance in the spinal column) (2), whereas the sham operation consisted of exposure but not section of the sciatic nerve in eight rats. All animals were killed by microwave irradiation 14 days after surgery. This time was chosen because data indicate that during the second postoperative week both behavioural and electrophysiological signs of neuropathy are evident (16).

For amino acid measurement, the hindbrain, midbrain and hypothalamus were dissected according to the technique of Glowinsky and Iversen (17). Hindbrain and midbrain were divided into the right and left sides. The brain areas were placed on an ice-cold Petri dish, weighed, frozen on dry ice and stored at $-80^{\circ} \mathrm{C}$ until assay. The tissue was homogenized with $10 \mathrm{~mL} / \mathrm{g}$ of $80 \%$ methanol, which contained ascorbic acid $(0.4 \mathrm{mM})$ as antioxidant and 5-aminovaleric acid $(100 \mathrm{mM})$ as internal standard for chromatographic assay. The homogenate was centrifuged and the supernatant stored at $-80^{\circ} \mathrm{C}$. A supernatant aliquot of $100 \mu \mathrm{L}$ of each sample was introduced into a $10 \mathrm{~mL}$ screw-capped tube and evaporated under nitrogen flow, then derivated with $35 \mu \mathrm{L}$ of sodium hydrogen carbonate $0.1 \mathrm{M}$ and $80 \mu \mathrm{L}$ of dansyl chloride $0.5 \%$ in acetone at $90^{\circ} \mathrm{C}$ for 15 mins. Glutamine, aspartic acid, glutamic acid and GABA were quantified by a high performance liquid chromatography method previously described and validated (18). Briefly, a Series 10 Perkin-Elmer liquid chromatograph (Perkin-Elmer, Connecticut) with a variable wavelength ultraviolet detector and a C8 Pecosphere column (Perkin-Elmer) ( $3 \mu \mathrm{m}$ particle size; $8 \mathrm{~cm} \times 46 \mathrm{~mm}$ ) were employed. The mobile phase was $19 \%$ acetonitrile in acetate buffer ( 0.25 sodium acetate), adjusted to $\mathrm{pH} 3.25$ with orthophosphoric acid. The flow rate was $1.8 \mathrm{~mL} / \mathrm{min}$ and the eluted derivatives were monitored at $254 \mathrm{~nm}$.

Statistical evaluation of results was carried out by one-way ANOVA.

\section{RESULTS}

Amino acid measurements were performed 14 days after surgery. As indicated in Figure 1, the experimental mononeuropathy was associated with a significant increase in glutamine (left side: $\mathrm{F}(1,15)=29.12, \mathrm{P}<0.0001$; right side: $\mathrm{F}(1,15)=47.79, \mathrm{P}<0.0001)$ and a significant decrease in GABA (left side: $F(1,15)=10.28, P=0.006$; right side: $\mathrm{F}(1,15)=15.88, \mathrm{P}<0.0001)$ in the midbrain. These biochemical modifications were similar on both sides of the brain, suggesting diffuse activation of the midbrain neurons irrespective of the side of the peripheral lesion. Comparable observations were performed at the hindbrain level. Glutamine concentrations were also significantly higher (left side: $\mathrm{F}(1,15)=55.86, \mathrm{P}<0.0001$; right side: $\mathrm{F}(1,15)=16.48, \mathrm{P}=0.001)$ and $\mathrm{GABA}$ concentrations were significantly lower (left side: $\mathrm{F}(1,15)=11.86, \mathrm{P}=0.004$; right side: $\mathrm{F}(1,15)=22.23, \mathrm{P}<0.0001)$ in the mononeuropathic animals than in sham-operated rats, with no distinction between the right and left side (Figure 2). Levels of aspartate and glutamate did not change after sciatic ligature in both the midbrain and hindbrain (Figures 


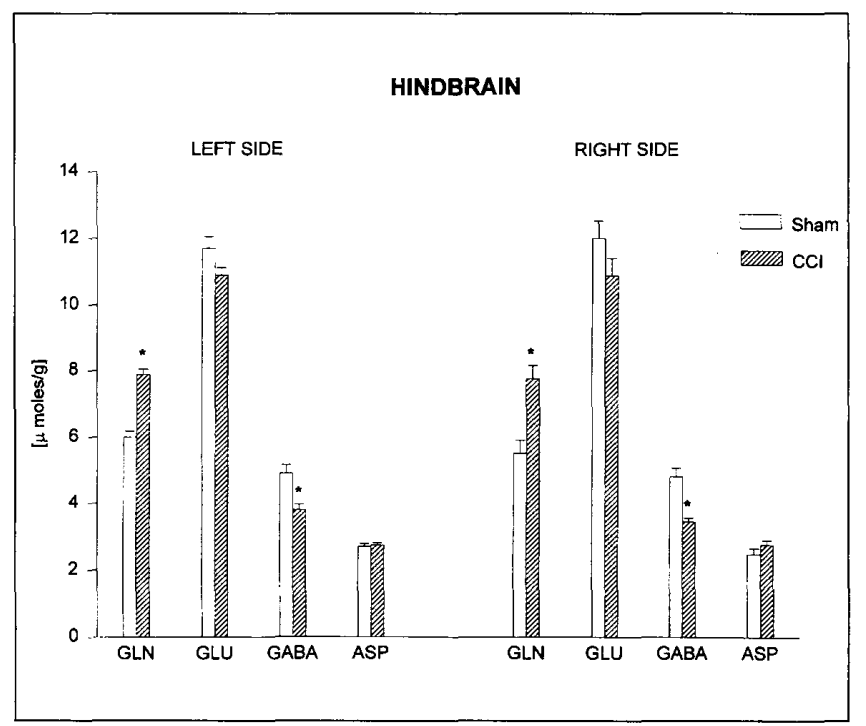

Figure 2) Amino acid levels measured in the rat hindbrain 14 days after loose ligature of the right sciatic nerve. Values are presented as mean \pm SEM of eight rats. *Significantly different from sham-operated animals. ASP Aspartic acid; CCI Chronic constriction injury; GABA Gamma-aminobutyric acid; GLN Clutamine; GLU Glutamic acid

$1,2)$. A significant increase in glutamine levels $(F(1,15)=21.53$, $\mathrm{P}<0.0001)$ and a decrease in GABA concentrations $(\mathrm{F}(1,15)=9.63$, $\mathrm{P}=0.008$ ) were likewise observed in the hypothalamus of rats with CCI (Figure 3).

The section of the sciatic nerve did not induce any change in amino acid levels in the midbrain and hindbrain (Table 1). Similarly, no difference in hypothalamic amino acid levels between sham-operated and deafferentated rats was observed (Table 1).

\section{DISCUSSION}

Several experimental observations indicate that functional and biochemical changes take place in the central nervous system after peripheral nervous system lesions $(8,19)$ and that these modifications also involve the supraspinal structures $(10,20)$. We $(10,11)$ previously described that $\mathrm{CCI}$ and deafferentation produced a completely different neuropeptide response at central levels. The aim of the present study was to ascertain whether these two different manipulations of a peripheral nerve induce diverse responses in the levels of amino acids in some regions of the rat brain involved in nociception $(15,21)$. Our present results seem to suggest that the different pattern of modifications observed after deafferentation or CCI may be due to a possible lack (after sciatic section) or surplus (after sciatic ligation) of inputs from the periphery to the brain areas involved in nociceptive signal modulation. Indeed, this study shows that the $\mathrm{CCI}$ - but not the section of the sciatic nerve - produces significant modifications of amino acid levels in the brain homogenates.

The fall in GABA levels observed in the midbrain, hindbrain and hypothalamus may indicate that GABA is involved in some modulatory task when $\mathrm{CCI}$ induces strong activations of several neuronal areas, both in the spinal cord and supraspinal areas (7,21). Because it is well known that GABA is an inhibitory transmitter in the adult central nervous system (22), the present observation of a decrease in GABA levels in these brain areas of $\mathrm{CCI}$ rats seems to be

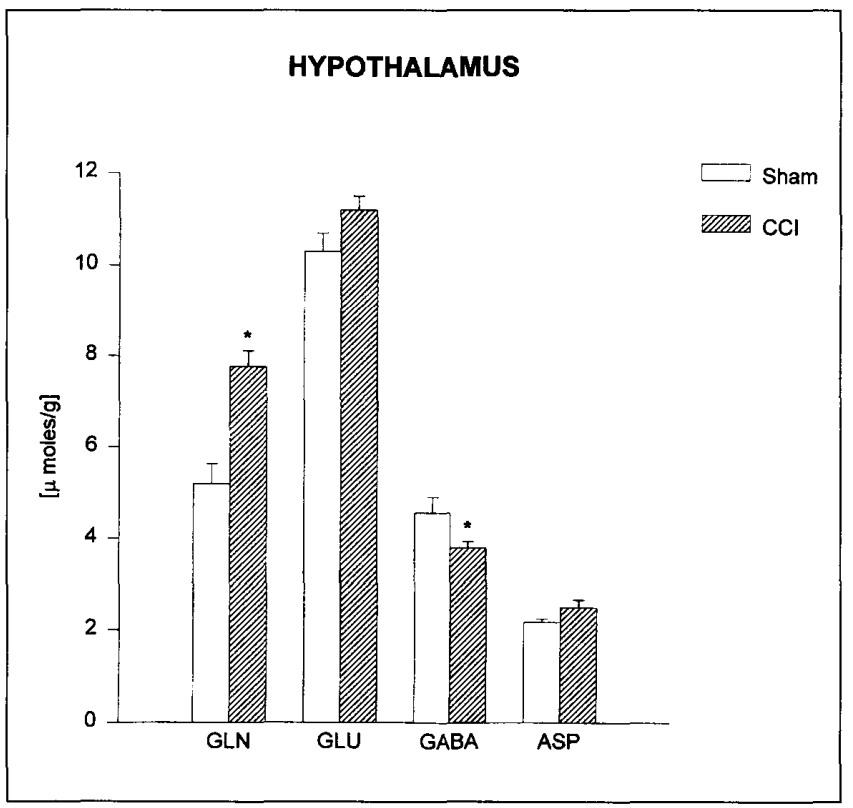

Figure 3) Hypothalamic amino acid levels measured 14 days after loose ligature of the right sciatic nerve. Values are presented as mean \pm SEM of eight rats. *Significantly different from sham-operated animals. ASP Aspartic acid; $\mathrm{CCl}$ Chronic constriction injury; GABA Gamma-aminobutyric acid; GLN Glutamine; GLU Glutamic acid

TABLE 1

Amino acid levels measured in the midbrain, hindbrain and hypothalamus 14 days after sectioning of the right sciatic nerve. Values are presented as mean \pm SEM of eight rats $(\mu \mathrm{mol} / \mathrm{g})$

\begin{tabular}{lcccc}
\hline & Glutamine & Glutamic acid & GABA & ASP \\
\hline $\begin{array}{l}\text { Left midbrain } \\
\quad \text { Sham }\end{array}$ & $6.2 \pm 0.4$ & $9.1 \pm 0.2$ & $2.6 \pm 0.2$ & $2.4 \pm 0.1$ \\
$\quad \begin{array}{l}\text { Section } \\
\text { Right midbrain }\end{array}$ & $5.9 \pm 0.3$ & $8.8 \pm 0.2$ & $2.4 \pm 0.2$ & $2.5 \pm 0.1$ \\
$\quad$ & & & & \\
$\quad$ Sham & $5.9 \pm 0.1$ & $8.9 \pm 0.3$ & $2.6 \pm 0.1$ & $2.4 \pm 0.2$ \\
$\quad$ Section & $5.6 \pm 0.1$ & $8.5 \pm 0.2$ & $2.4 \pm 0.1$ & $2.7 \pm 0.2$ \\
Left hindbrain & & & & \\
$\quad$ Sham & $5.7 \pm 0.5$ & $10.6 \pm 0.7$ & $4.7 \pm 0.5$ & $2.5 \pm 0.2$ \\
$\quad$ Section & $5.8 \pm 0.8$ & $10.4 \pm 0.2$ & $4.5 \pm 0.4$ & $2.5 \pm 0.1$ \\
Right hindbrain & & & & \\
$\quad$ Sham & $5.1 \pm 0.2$ & $10.4 \pm 0.4$ & $4.8 \pm 0.2$ & $2.6 \pm 0.1$ \\
$\quad$ Section & $5.4 \pm 0.2$ & $10.7 \pm 0.4$ & $4.7 \pm 0.2$ & $2.5 \pm 0.1$ \\
Hypothalamus & & & & \\
$\quad \begin{array}{l}\text { Sham } \\
\text { Section }\end{array}$ & $5.3 \pm 0.4$ & $10.1 \pm 0.4$ & $4.6 \pm 0.3$ & $2.2 \pm 0.1$ \\
\hline ASP Aspartic acid & $5.1 \pm 0.4$ & $10.4 \pm 0.4$ & $4.0 \pm 0.3$ & $2.1 \pm 0.1$ \\
\hline
\end{tabular}

ASP Aspartic acid; GABA Gamma-aminobutyric acid

consistent with our previous hypothesis that chronic pain and hyperalgesia connected with peripheral nerve injury cause an activation of endogenous inhibitory systems that controls nociceptive afferents to supraspinal areas (11). Regarding the enhanced levels of glutamine observed after CCI, the whole biochemical pathway from glutamine to GABA may undergo temporary modifications. Likewise, the levels of glutamine, glutamate and GABA could present different 
temporal peaks in relation to the enzymatic processes. Further specific observations are needed if we are to understand the significance of amino acid level modification to the events triggered by CCI.

It has been demonstrated that GABA is also related to the oxidative metabolism of carbohydrates in the central nervous system by means of a 'shunt' involving its production from glutamate (22). However, because we did not observe any modification of glutamate levels, it seems reasonable to conclude that carbohydrate

\section{REFERENCES}

1. Seltzer $Z$. The relevance of animal neuropathy models for chronic pain in humans. Sem Neurosci 1995;7:211-9.

2. Panerai AE, Sacerdote P, Brini A, Bianchi M, Mantegazza P. Autotomy and central nervous system neuropeptides after section of the sciatic nerve in rats of different strains. Pharmacol Biochem Behav 1987;28:385-8.

3. Devor M, Wall PD. The effect of peripheral nerve injury on receptive fields of cells in the cat spinal cord. J Comp Neurol 1981;199:277-93.

4. Bennett GJ, Xie YK. A peripheral mononeuropathy in rat that produces disorders of pain sensation like those seen in man. Pain 1988;33:87-107.

5. Laird JMA, Bennett GJ. An electrophysiological study of dorsal horn neurons in the spinal cord of rats with an experimental peripheral neuropathy. J Neurophysiol 1993;69:2072-85.

6. Cameron AA, Cliffer KD, Dougherty RM, Willis WD, Cariton SM. Changes in lectin, GAP-43 and neuropeptide staining in the rat superficial dorsal horn following experimental peripheral neuropathy. Neurosci Lett 1991;131:249-52.

7. Sotgiu ML. Descending influence on dorsal horn neuronal hyperactivity in a rat model of neuropathic pain. Neuroreport 1993;4:21-4.

8. Al-Ghoul WM, Li Volsi G, Weinberg RJ, Rustioni A. Glutamate immunochemistry in the dorsal horn after injury or stimulation of the sciatic nerve of rats. Brain Res Bull 1993;30:453-9.

9. Skilling SR, Smullin DH, Beitz AJ, Larson AA. Extracellular amino acid concentrations in the dorsal spinal cord of freely moving rats following veratridine and nociceptive stimulation. J Neurochem $1988 ; 51 ; 127-32$.

10. Panerai AE, Sacerdote P, Brini A, Bianchi M, Mantegazza P. Central nervous system neuropeptides after peripheral nerve deafferentation. Peptides 1988;9:319-24.

11. Bianchi M, Sotgiu ML, Manfredi B, Sacerdote P. Peripheral mononeuropathy affects hypothalamic and splenocyte beta-endorphin levels but not immune function in the rat. Brain Res Bull 1996;40:269-72. metabolism is not involved in the biochemical changes induced by $\mathrm{CCI}$ in the midbrain, hindbrain and hypothalamus.

\section{CONCLUSIONS}

Our findings indicate that $\mathrm{CCI}$ - but not sectioning of the sciatic nerve - produces measurable biochemical modifications in the rat brain areas involved in nociception. Moreover, our results suggest that the persistent irritative stimulus established by $\mathrm{CCI}$ is able to trigger amino acid-modulated processes at a supraspinal level.

12. Reichling DB, Basbaum AI. Contribution of brainstem GABAergic circuitry to descending antinociceptive controls: I. GABAimmunoreactive projection neurons in the periaqueductal gray and nucleus raphe magnus. J Comp Neurol 1990;302:270-7.

13. Urban L, Thomson SWN, Dray A. Modulation of spinal excitability: co-operation between neurokinin and excitatory amino acid neurotransmitters. Trends Pharmacol Sci 1994;17:432-8.

14. Wang $Q$, Nakay $Y$. The dorsal raphe: an important nucleus in pain modulation. Brain Res Bull 1994;34:575-85.

15. Dafny N, Dong QW, Prieto-Gomez C, Reyes-Vazquez C, Stanford J, Qiao JT. Lateral hypothalamus: site involved in pain modulation. Neuroscience 1996;70:449-60.

16. Attal N, Jazat F, Kayser V, Guilbaud G. Further evidence for "pain related" behaviours in a model of unilateral peripheral mononeuropathy. Pain 1990;41:235-51.

17. Glowinsky J, Iversen LL. Regional studies of catecholamines in rat brain. J Neurochem 1966;13:655-9.

18. Zonta N, Ferrario P, Di Giulio AM, Zecca L, Gorio A, Mantegazza P. Neurochemical changes of long-term adrenalectomy in rat brain: effects on neurotransmitter amino acids. Int J Dev Neurosci 1002; $10: 439-45$.

19. Ossipov MH, Lopez Y, Nichols ML, Bian D, Porreca F. Inhibition by spinal morphine of the tail-flick response is attenuated in rats with nerve ligation injury, Neurosci Lett 1995; 199:83-6.

20. Bucinskaite V, Lundeberg T, Stenfors C, Belfrage M, Hansson P, Theordorsson $\mathrm{E}$. Changes of neuropeptide concentrations in the brain following experimentally induced mononeuropathy in Wistar Kioto and spontaneously hypertensive rats. Neurosci Lett 1995;192:93-6.

21. Guilbaud G, Benoist JM, Jazat F, Gautron M. Neuronal responsiveness in the ventrobasal thalamic complex of rats with an experimental peripheral mononeuropathy. J Neurosci 1990;64:1537-54.

22. Cooper JR, Bloom FE, Roth RH. Amino acid transmitters. In: House J, ed. The Biochemical Basis of Neuropharmacology, 6th edn. New York: Oxford University Press, 1991:133-72. 


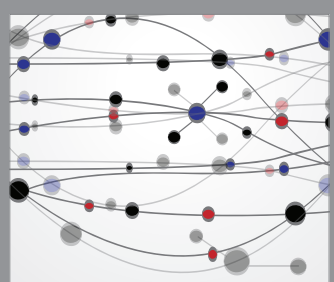

The Scientific World Journal
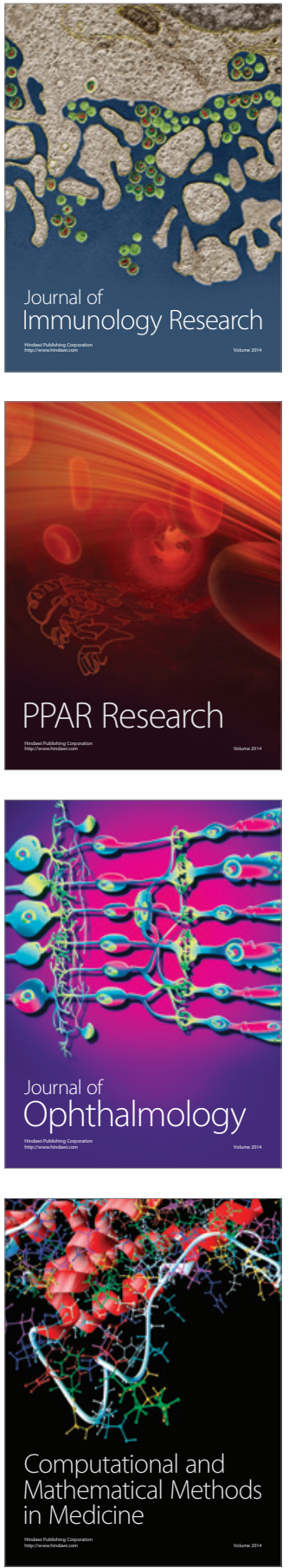

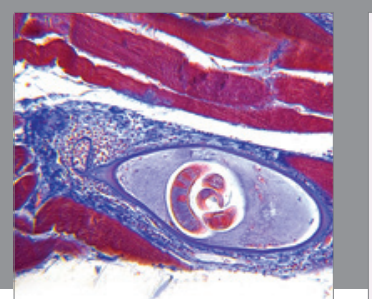

Gastroenterology Research and Practice

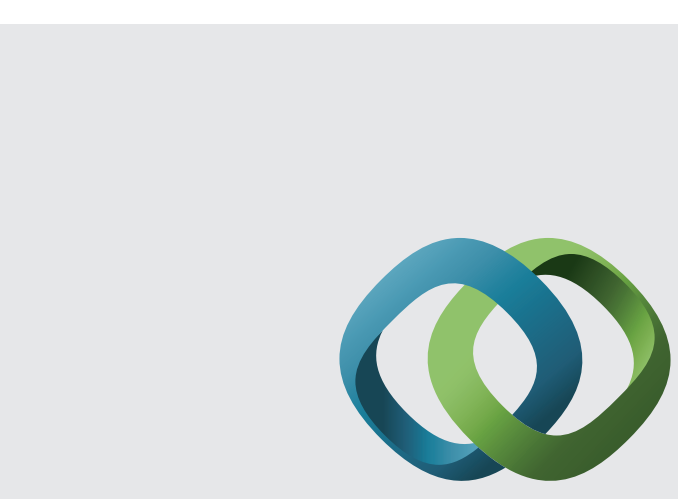

\section{Hindawi}

Submit your manuscripts at

http://www.hindawi.com
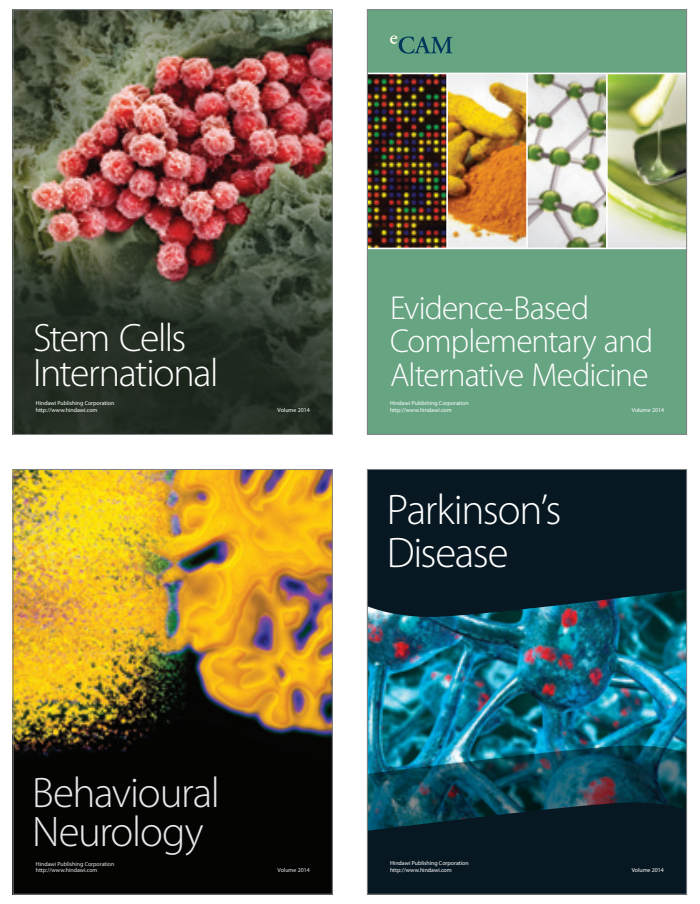
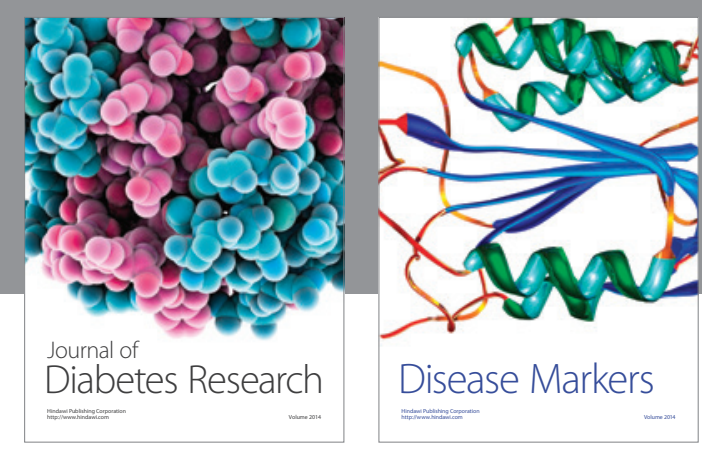

Disease Markers
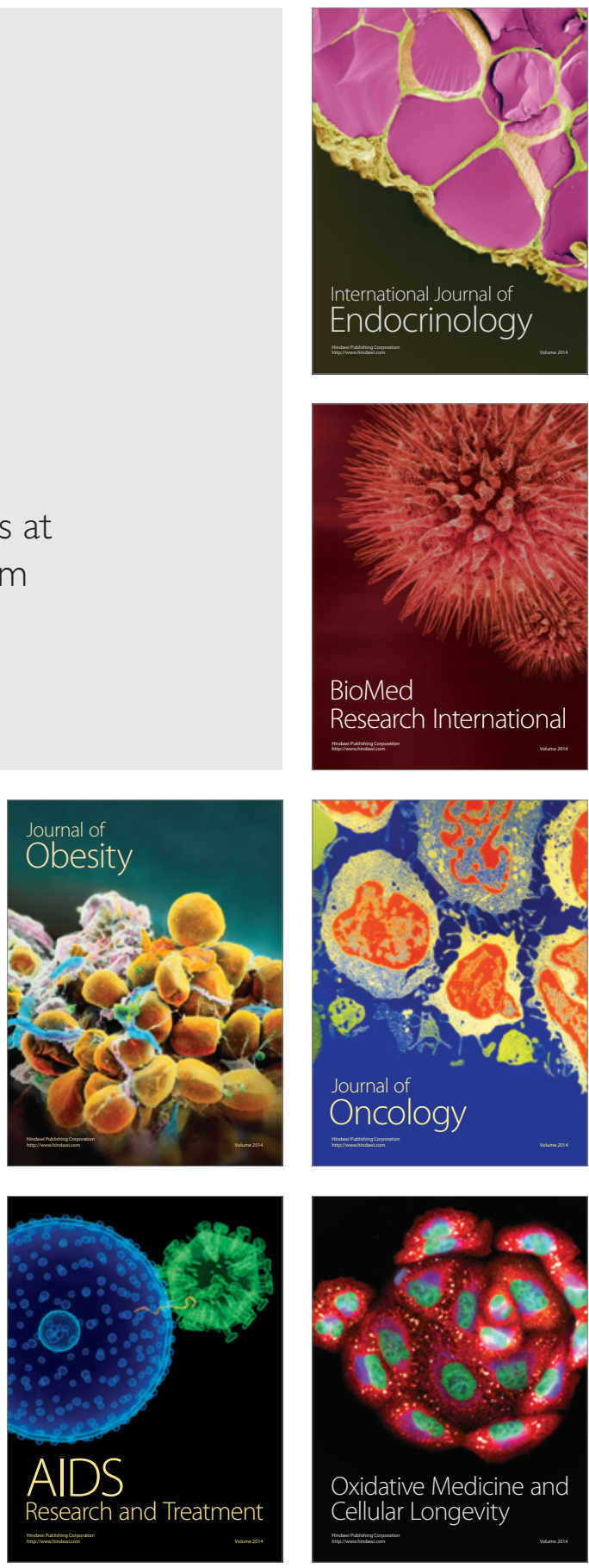